\title{
PERFILDOS ASPECTOS FÍSICOS, FISIOLÓGICOS E QUÍMICOS DE SEMENTES DE SOJA PRODUZIDAS EM SEIS REGIÕES DO BRASIL ${ }^{1}$
}

\author{
NILTON PEREIRADACOSTA², CEZAR DE MELLO MESQUITA², ANTONINHO CARLOS MAURINA4 ${ }^{4}$, JOSÉ BARROS FRANÇANETO², \\ FRANCISCO CARLOS KRZYZANOWSKI ${ }^{2}$, MARIACRISTINANEVES OLIVEIRA ${ }^{3}$, ADEMIRASSIS HENNING $^{2}$
}

\begin{abstract}
RESUMO - A semente de soja, produzida em algumas regiões do Brasil, tem apresentado sérios problemas de qualidade fisiológica. Essa situação pode ser atribuída a ajustes inadequados do sistema de trilha das colhedoras, à ocorrência de estresses climáticos na maturação e, geralmente, à lesões de percevejos, resultando em semente com baixos potenciais de germinação e de vigor. $\mathrm{O}$ estudo teve como objetivo avaliar o comportamento da qualidade da semente produzida em diferentes regiões produtoras de soja e identificar locais com condições edafoclimáticas ideais para sua produção com melhor potencial qualitativo. Foram avaliadas 364 amostras de diferentes cultivares de soja, coletadas diretamente do tanque graneleiro das colhedoras, nos estados do Paraná, Minas Gerais, Mato Grosso do Sul e Mato Grosso (região de Alto Garça). Para diagnosticar o desempenho da qualidade, empregaram-se os seguintes parâmetros: grau de umidade, germinação, sementes quebradas e testes de hipoclorito e tetrazólio, este para estimar vigor, viabilidade, dano mecânico, deterioração por umidade e lesões de percevejos, além de análise química. Os resultados indicaram que índices elevados de danos mecânicos, de quebra e de ruptura de tegumento, quando associados a percentuais acentuados de deterioração por umidade e de ataque de percevejo afetaram, em maior intensidade, a qualidade da semente proveniente de Minas Gerais, do Mato Grosso do Sul e das regiões norte e oeste do Paraná, quando comparados com àquelas oriundas do Estado do Mato Grosso e da região sul do Paraná. Nos Estados do Mato Grosso e região sul do Paraná, existem áreas com potencial climático, para produção de sementes de soja com elevada qualidade fisiológica. Existem regiões nos Estados de Minas Gerais, Paraná e Mato Grosso que produzem sementes de soja com maiores teores de proteínas e óleo e com acidez relativamente baixa.
\end{abstract}

Termos para indexação: Glycine max, viabilidade, vigor, dano mecânico.

\section{PROFILE OF THE PHYSICAL, PHYSIOLOGICAL AND CHEMICALASPECTS OF SOYBEAN SEEDS PRODUCED IN SIX REGIONS OF BRAZIL}

ABSTRACT - Soybean seeds, produced in some areas of Brazil, have presented serious problems of physiological quality. This has been attributed to inadequate fittings of the harvesting system, climatic stress occurrence at maturation and stinkbug lesions, resulting in seed with low germination and vigor. The objective of this study was to evaluate the quality of soybean seeds produced in different areas and to identify the best edaphoclimatic regions for high quality seed production. During the 2001/2002 soybean crop, 364 samples, including different cultivars, were collected directly from the grain reservoir of the combine during harvesting in the States of Parana, Minas Gerais, Mato Grosso do Sul and Mato Grosso. The seeds were evaluated based on the following parameters: tetrazolium test (to estimate vigor, viability, field deterioration, mechanical damage and bug attack); germination (\%), vigour (TZ 1-3), viability (TZ 1-5), oil, protein and acidity content. The results showed that the high levels of breakage, mechanical damage and tegument rupture which were associated with damage caused by moisture and sting bug, affected the quality of seeds produced in Minas Gerais, Mato Grosso do Sul, North and the Western regions of Parana,

${ }^{1}$ Submetido em 15/06/2004 e Aceito em 31/03/2005. Manuscrito aprovado pelo Chefe Adjunto de Pesquisa e Desenvolvimento da Embrapa Soja, sob o $\mathrm{n}^{\circ} 16 / 2004$

${ }^{2} \mathrm{Eng}^{\mathrm{o}} \mathrm{Agr}^{\mathrm{O}}, \mathrm{PhD}$, pesquisador, Embrapa Soja, Cx. Postal 231, 86.001-970,
Londrina-PR. Bolsita do CNPq. nilton@cnpso.embrapa.br.

${ }^{3}$ Lic. Matemática, Doutorada-Pesquisadora, Embrapa Soja.

${ }^{4}$ Eng $^{\circ}$ Agr $^{\circ}$, extensionista, Emater/PR, Cx. Postal 1662, 80035-270, CuritibaPR. 
when compared with seeds produced in the Southern region of Parana and Mato Grosso. In the states of Mato Grosso and South region of Paraná there are regions with potential climatic for soybean seed production of high physiological quality. There are regions in the states of Minas Gerais, Paraná and Mato Grosso that produce soybean seeds with high protein and oil content and with lower acidity contend.

Index terms: Glycine max, viability, vigor, mechanical damage.

\section{INTRODUÇÃO}

A crescente expansão da cultura da soja na região tropical do Brasil devido ao seu alto potencial de produtividade tem uma séria limitação, onde parte expressiva dos produtores de sementes, geralmente emprega tecnologias inadequadas, resultando na obtenção de um produto com qualidade comprometida. Além desses aspectos, deve-se enfatizar que a colheita mecânica da soja é considerada uma etapa economicamente de custos elevados e, quando não realizada em tempo hábil e com máquinas devidamente ajustadas, pode resultar num padrão de sementes de acentuada variabilidade.

A literatura tem indicado que a fase compreendida entre a maturidade fisiológica e a morfológica da semente pode ser considerada como um período de "armazenagem” a campo, durante o qual raramente as condições climáticas são favoráveis à preservação da qualidade, principalmente nas regiões tropicais e subtropicais (Costa et al., 1994). Também, deve ser enfatizado que oscilações de temperaturas acompanhadas de altos índices pluviais e flutuação de umidade relativa do ar nas fases de maturação e pré-colheita da semente, geralmente possibilitam em perdas na sua qualidade física, fisiológica e sanitária, em parte expressiva de regiões produtoras de sementes de soja (Costa et al., 2001). A respeito do tema, Carter e Hartwig (1962), Tekrony et al. (1980), Viera et al. (1982) e Costa et al. (1994) detectaram que baixas temperaturas favorecem a qualidade da semente e que condições quentes e úmidas, com excesso de precipitação, poderão afetar de forma irreversível a germinação e o vigor das sementes produzidas nessas regiões. Dentro desse raciocínio, Dajoz (1981), Costa et al. (1994), França Neto e Krzyzanowski (2000) e Costa et al. (2001) argumentam que, para as condições tropicais brasileiras, onde predominam altas temperaturas e excesso de chuvas no período de maturação da soja, a alternativa mais viável para produção de sementes de alta qualidade, seria a escolha de regiões com altitude superior a 700m, onde predomine clima frio e seco no período da maturação a colheita, ou mesmo o ajustamento da data de semeadura, para ocorrência da maturação em condições ambientais mais favoráveis.

Além dos aspectos comentados, sabe-se que a semente de soja, apresenta as partes vitais do embrião, como radícula, hipocótilo e plúmula, situados sob um tegumento pouco espesso que, praticamente, não lhes oferece proteção, levando, na maioria dos casos, a uma maior incidência de danos mecânicos na colheita, beneficiamento, transporte e armazenamento. Entretanto, pode-se, também mencionar que existe a demanda de estudos de regulagens dos diferentes sistemas de trilha mecânica, associadas aos diferentes graus de umidade da semente na colheita, visando à redução dos níveis de danos mecânicos que ocorrem nas sementes de soja (Mesquita, 1989). Esse tipo de dano tem sido considerado como o mais nocivo à qualidade das sementes de soja produzidas no Brasil (Carbonel et al., 1998).

Ainda tem sido observado, que o sistema de trilha utilizado pela maioria das colhedoras, é responsável pelas ações simultâneas de impacto, compressão e atrito transmitidos às sementes/grãos das plantas, que são levadas a passar entre o cilindro de trilha e o côncavo durante a colheita. Como conseqüência dessa ação agressiva, sementes ou grãos colhidos poderão ser fragmentados, quebrados, triturados e danificados em diferentes níveis de tamanhos. Segundo Skromme (1977), as colhedoras com sistema de trilha axial, apresentam maior capacidade de colheita e permitem a redução dos índices de danos mecânicos em relação às colhedoras com sistema de trilha com alimentação tangencial. Todavia, os custos de aquisição desse modelo de colhedora ainda são elevados, para a maioria dos produtores de sementes do Brasil.

A resistência da semente de soja ao dano mecânico está relacionada com os níveis de lignina encontrados no tegumento: genótipos de soja com mais de 5,5\% de lignina no tegumento têm sementes e grãos com maior resistência e, por conseguinte, apresentam boa qualidade física e fisiológica (Alvarez et al., 1997). De acordo com Gasparetto et al. (1977), o que se espera de um mecanismo de trilha é a eliminação das perdas de sementes durante o processo de colheita, redução dos danos mecânicos macro e microscópicos transmitidos às sementes e uma separação eficaz das sementes. 
Outro fator que pode afetar o desempenho de sementes de soja é o que resulta das lesões de percevejos, principalmente, devido à colonização dos tecidos das sementes por Nematospora coryli Peglion, o qual provoca acentuada deterioração. O período crítico de incidência desse inseto, de acordo com Panizzi et al. (1979), está compreendido entre os estádios de desenvolvimento e de enchimento de vagens. Nessa fase, o controle da praga deve ser realizado quando forem encontrados dois percevejos por metro linear em lavouras comerciais e um percevejo por metro linear, em lavouras destinadas a produção de sementes. Os autores, ainda, observaram que alta proporção de microrganismos estava associada com sementes danificadas por Piezodorus guildinii, dentre esses, Fusarium sp. que infectou percentuais superiores a mais 30\% das sementes lesionadas.

O presente estudo teve como objetivo avaliar a qualidade física, fisiológica e química de sementes resultantes da colheita mecânica, realizada em diferentes localidades produtoras de soja do Brasil e identificar as regiões com as melhores condições edafoclimáticas para produção de sementes de alta qualidade.

\section{MATERALE MÉTODOS}

Para execução do estudo, foram coletadas 364 amostras de sementes de cultivares de soja, produzidas nos estados do Paraná, Mato Grosso do Sul, Minas Gerais e Mato Grosso (região de Alto Garça). Do Paraná foram analisados as cultivares BR-16, BR-36, COODETEC-201, COODETEC202, COODETEC-203, COODETEC-205, COODETEC-206, Embrapa 48, Embrapa 59, FT-Abyara e OCEPAR 13; do Mato Grosso do Sul, foram avaliadas as cultivares Embrapa 48, BRS-133, BRS-133, BRS-182, BRS-206, COODETEC-208; de Minas Gerais, foram avaliadas as cultivares COODETEC201, MG/BRS 56 (Confiança), MG/BR 46 (Conquista), MG/ BR 48, MT/BR-45, DM Vitória, UFV-18, UFV-19, Msoy 8001, Msoy 9001; de Mato Grosso, foram analisadas as cultivares MG/BR 46 (Conquista), BRSMT (Pintado), MT/BR 51 (Xingú) e FMT (Arara Azul). As amostras, pesando aproximadamente $3 \mathrm{~kg}$, foram retiradas do tanque graneleiro das colhedoras no ato da colheita. O teor de água das sementes/ grãos foi determinado por aparelhos portáteis no campo ou em laboratórios e, em seguida, as amostras foram embaladas em sacos de pano e enviando-as a Embrapa Soja, para a execução das análises laboratoriais.

As colhedoras, independentemente dos modelos, ano de fabricação, marcas usadas e regiões de amostragem, foram agrupadas, para fins de avaliação da qualidade de trilha, em três faixas de velocidade do cilindro: $\leqslant 500 \mathrm{rpm}$; entre 500rpm e 700rpm e $\geq 700 \mathrm{rpm}$. Deve-se ainda informar que o referido trabalho envolveu cerca de 364 lavouras, empregando-se um universo expressivo de colhedoras, não permitindo detalhes de outros componentes da máquina, pela razão óbvia da amplitude das regiões de abrangência e pelo grande número de colhedoras.

Os parâmetros utilizados para avaliar a qualidade das sementes foram: grau de umidade, características físicas (sementes quebradas e ruptura de tegumento); características fisiológicas, germinação e tetrazólio (vigor, viabilidade, dano mecânico, deterioração por umidade e lesões de percevejos) e características químicas (teores de óleo, proteína e sua respectiva acidez). O teste de germinação foi realizado com quatro subamostras de 50 sementes para cada amostra. As sementes foram semeadas em rolo de papel (tipo germitest) e colocadas em germinador a $25^{\circ} \mathrm{C}$; a contagem foi efetuada no quinto dia após a semeadura, segundo (Brasil, 1992). Os dados obtidos foram expressos em percentagens de plântulas normais. Para a condução do teste de tetrazólio, utilizaram-se 100 sementes de cada cultivar, as quais foram acondicionadas em papel germitest, durante 16 horas, em temperatura ambiente. Passado esse período, as sementes foram retiradas e colocadas em copos bequer, numa solução de concentração de $0,075 \%$ de 2,3,5-trifenil cloreto de tetrazólio e colocadas no escuro, em estufa, com temperatura variando entre 35 a $40^{\circ} \mathrm{C}$, pelo período de três horas. Após a lavagem em água corrente, as sementes foram analisadas individualmente, verificando-se percentagem de vigor (TZ 1-3), de viabilidade (TZ 1-5), de danos mecânicos (TZ 6-8), de lesões de percevejos (TZ 6-8) e de deterioração por umidade (TZ 6-8), conforme metodologia sugerida por França Neto et al. (1998). Essas variáveis podem ser facilmente identificadas pelo teste de tetrazólio, conforme ilustrado na Figura 1. Para avaliar a ruptura de tegumento, foram utilizadas duas subamostras de 50 sementes cada, colocadas em placa de Petri e cobertas com hipoclorito de sódio (5\%), por um período de 15 minutos. Em seguida, eliminou-se o excesso de solução, distribuindo as sementes sobre duas folhas de papel germitest e procedendo a contagem do número de sementes com tegumentos rompidos. Os dados obtidos foram apresentados em percentagem conforme descrito por Vaughan (1982). Já para a avaliação de sementes quebradas seguiu-se a metodologia prescrita e sugerida por Mesquita et al. (1999). Para a avaliação dos teores de proteína, óleo e sua respectiva acidez, foi usada metodologia proposta por Pregnolatto e Pregnolatto (1985). 

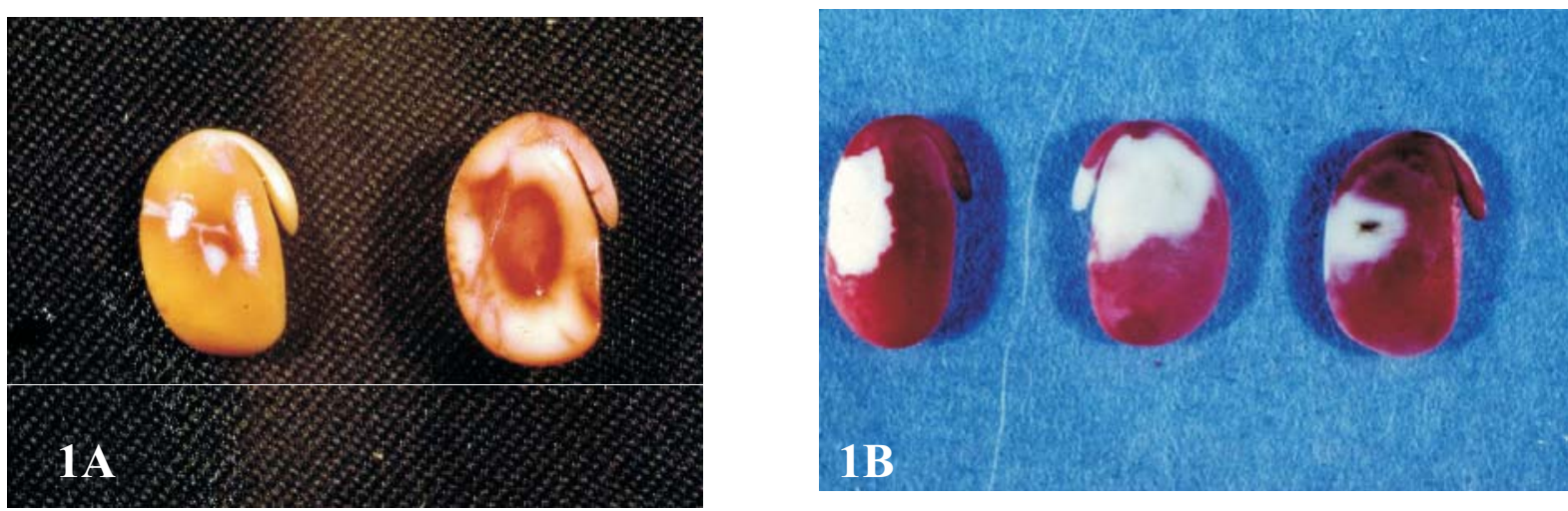

FIGURA 1. Sementes de soja apresentando sintomas de dano mecânico (1A) e de lesões de percevejos (1B), avaliados pelo teste de tetrazólio, afetando o vigor e a viabilidade [TZ (1-3 e 1-5)].

Todos os dados obtidos foram analisados individualmente, considerando um delineamento inteiramente casualizado com um fator de classificação. As análises estatísticas para as variáveis respostas estudadas foram realizadas pelo programa SAS Statistical Analysis System-SAS por meio do módulo GLM, segundo critérios adotados por (Cochran e Cox, 1957). Para comparação múltipla de médias foi usado o teste de Tukey $(P \leqslant 0,05)$. Para maior sustentação e suporte na discussão dos resultados foram determinados ainda os coeficientes de variação de cada análise efetuada. Foram também aplicadas as análises de correlação e regressão linear e determinados os coeficientes de correlação (r) e de determinação $\left(R^{2}\right)$ entre as diferentes variáveis respostas do estudo, de acordo com Freire et al. (1999).

\section{RESULTADOS E DISCUSSÃO}

A análise estatística dos resultados indica percentuais elevados de danos mecânicos, que interagindo com sementes deterioradas e lesionadas por percevejos, comprometeram significativamente a qualidade das sementes. Confrontandose os resultados contidos na Figura 2 e nas Tabelas 1 e 2, o teste de Tukey $(\mathrm{P} \leqslant 0,05)$ mostrou que regiões consideradas estratégicas na produção de sementes, como o sul do Paraná e região de Alto Garça, MT, principalmente, em função de condições climáticas amenas no período de maturação da soja, foram também sensivelmente afetadas por acentuados níveis de ruptura de tegumento, quebra de sementes e por danos mecânicos, que proporcionaram perdas significativas da qualidade fisiológica.

Por outro lado, detectou-se que quando a velocidade do cilindro de trilha operava até 500rpm, a qualidade física das sementes apresentou um melhor comportamento, porém,

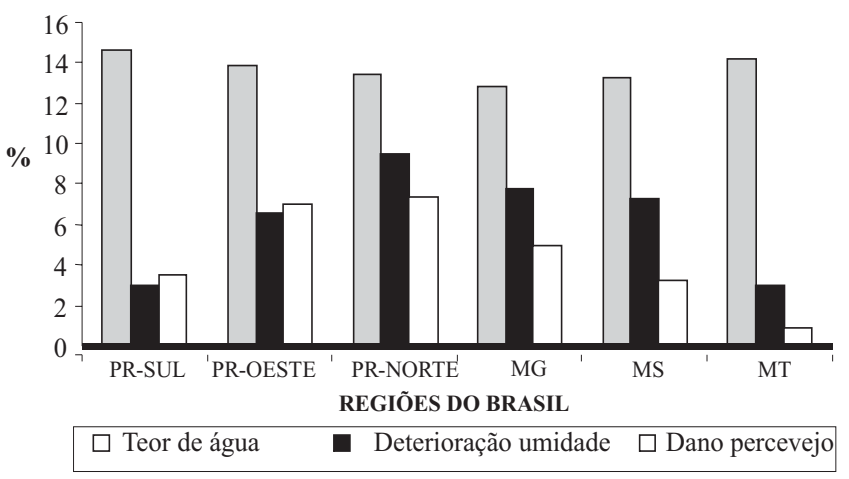

FIGURA 2. Resultados médios de grau de umidade (\%), deterioração por umidade (TZ 6-8) e de lesões de percevejos (TZ 6-8) de sementes de diversos cultivares de soja, produzidas em seis regiões do Brasil.

TABELA 1. Qualidade física das sementes provenientes da colheita mecânica da soja, em seis regiões produtoras do Brasil.

\begin{tabular}{lccc}
\hline Regiões & $\begin{array}{c}\text { Dano Mecânico } \\
(\text { TZ 6-8) }\end{array}$ & $\begin{array}{c}\text { Sementes } \\
\text { Quebradas (\%) }\end{array}$ & $\begin{array}{c}\text { Ruptura de } \\
\text { Tegumento (\%) }\end{array}$ \\
\hline Paraná - Sul & $12,9 \mathrm{ab}^{1}$ & $5,4 \mathrm{a}$ & $14,9 \mathrm{~b}$ \\
Paraná - Oeste & $12,1 \mathrm{ab}$ & $8,5 \mathrm{a}$ & $19,6 \mathrm{a}$ \\
Paraná - Norte & $14,6 \mathrm{ab}$ & $8,8 \mathrm{a}$ & $22,3 \mathrm{a}$ \\
Minas Gerais & $15,6 \mathrm{a}$ & $9,4 \mathrm{a}$ & $19,4 \mathrm{a}$ \\
Mato Grosso do Sul & $11,0 \mathrm{cb}$ & $7,4 \mathrm{~b}$ & $15,0 \mathrm{~b}$ \\
Mato Grosso & $8,0 \mathrm{c}$ & $4,7 \mathrm{~b}$ & $14,3 \mathrm{~b}$ \\
\hline CV (\%) & 54,9 & 60,3 & 38,0 \\
\hline
\end{tabular}

${ }^{1}$ Médias seguidas pela mesma letra, na coluna, não diferem entre si, pelo teste de Tukey a 5\% de probabilidade

quando ocorreu acréscimo na velocidade do cilindro para 500700rpm e superior a 700rpm, a qualidade física foi severamente afetada, propiciando redução do potencial de germinação e do vigor das sementes (Tabelas 3 e 4).

Os resultados ainda mostraram declínio de desempenho 
TABELA 2. Qualidade fisiológica de sementes provenientes da colheita mecânica da soja, em seis regiões produtoras do Brasil.

\begin{tabular}{lccc}
\hline \multicolumn{1}{c}{ Regiões } & Germinação (\%) & Vigor (\%) & Viabilidade (\%) \\
\hline Paraná - Sul & $83,0^{1} \mathrm{a}$ & $68,0 \mathrm{ab}$ & $82,0 \mathrm{ab}$ \\
Paraná - Oeste & $70,0 \mathrm{~b}$ & $58,2 \mathrm{~cd}$ & $75,4 \mathrm{bcd}$ \\
Paraná - Norte & $64,0 \mathrm{c}$ & $51,0 \mathrm{~d}$ & $69,5 \mathrm{~d}$ \\
Minas Gerais & $69,0 \mathrm{~b}$ & $56,6 \mathrm{~cd}$ & $72,7 \mathrm{~d}$ \\
Mato Grosso do Sul & $73,0 \mathrm{~b}$ & $63,3 \mathrm{bc}$ & $79,0 \mathrm{bc}$ \\
Mato Grosso & $85,7 \mathrm{a}$ & $76,0 \mathrm{a}$ & $88,4 \mathrm{a}$ \\
\hline CV (\%) & 23,0 & 24,7 & 15,9 \\
\hline
\end{tabular}

${ }^{1}$ Médias seguidas pela mesma letra, na coluna, não diferem entre si, pelo teste de Tukey a 5\% de probabilidade.

fisiológico das sementes, quando estas apresentavam níveis acentuados de ruptura de tegumento (\%), quebra (\%) e danos mecânicos (TZ 6-8) que na maioria de vezes podem afetar o comportamento da germinação e vigor (Figuras 3, 4, 5 e 6). Observou-se, através das análises de regressão linear, que a associação entre as variáveis testadas foi sempre inversamente proporcional e com valores relativamente baixos de coeficiente de determinação $\left(\mathrm{R}^{2}\right)$, os quais variaram de 0,075 a 0,404. Essa situação indica a existência de outros fatores envolvidos nas análises das sementes, os quais geralmente interagem fortemente e proporciona redução gradual do $\left(\mathrm{R}^{2}\right)$ obtido.

De acordo com os conceitos, projeções e averiguações efetuadas por diversos estudos, como Bunch (1962), Andrews (1965), Green et al. (1966), Delouche (1967), Moore (1972), Gasparetto (1977), Atares (1990), Costa et al. (1996), Mesquita et al. (1999) e Costa et al. (2003), os quais afirmam que, os mecanismos responsáveis pela agressividade do sistema de trilha e inadequação deste com abertura de côncavo, permitem à obtenção na maioria dos casos, de sementes seriamente afetadas, e como conseqüência, perdas substanciais de germinação e vigor, que dependendo do destino de comercialização, poderá ocorrer prejuízos econômicos importantes, principalmente, se o destino da matéria prima for para a indústria de sementes de soja. Reforçando os resultados obtidos, Copeland (1972) destaca que o dano mecânico ocorrido na colheita, pode acarretar redução na germinação da ordem de $10 \%$, e que o beneficiamento inadequado pode elevar esse índice para $20 \%$ ou mesmo para $30 \%$. Os danos mecânicos mesmo muitos pequenos (minidanificações), são capazes de reduzir a germinação de um lote de sementes em cerca de 1 a 2 pontos percentuais. No caso da soja, por exemplo, em que o número de sementes por grama varia de 6 a 13, queda de 1 ponto no percentual de germinação, significa em 1 tonelada, uma redução de 60.000 a 130.000 no número de sementes com capacidade de germinação.

Além dos aspectos mencionados, os resultados indicaram que a deterioração por umidade, danos mecânicos e de lesões de percevejos, potencializam de forma irreversível os sérios problemas da baixa qualidade fisiológica das sementes, principalmente, quando produzidas nas regiões norte e oeste do Paraná, Minas Gerais e Mato Grosso do Sul. Os resultados contidos na Figura 2 e nas Tabelas 1 e 2 destacam através da aplicação do teste de comparação de médias por Tukey ( $\mathrm{P}$ క $0,05)$, que quando os fatores deterioração por umidade, dano mecânico e lesões de percevejos agem conjuntamente, afetam sistematicamente o comportamento fisiológico das sementes. Os resultados ainda indicaram que, na região sul do Paraná e

TABELA 3. Médias das características fisiológicas e físicas de sementes de soja, provenientes de seis regiões produtoras do Brasil, colhidos sob o regime de velocidade do cilindro de trilha.

\begin{tabular}{cccccc}
\hline $\begin{array}{c}\text { Velocidade do } \\
\text { Cilindro (rpm) }\end{array}$ & Germinação (\%) & $\begin{array}{c}\text { Vigor (\%) } \\
(\text { TZ 1-3) }\end{array}$ & $\begin{array}{c}\text { Viabilidade (\%) } \\
(\text { TZ 1-5) }\end{array}$ & $\begin{array}{c}\text { Dano Mecânico } \\
(\text { TZ 6-8) }\end{array}$ & $\begin{array}{c}\text { Grau de } \\
\text { Umidade }(\%)\end{array}$ \\
\hline 5500 & $76,8 \mathrm{a}^{1}$ & $65,8 \mathrm{a}$ & $80,7 \mathrm{a}$ & $10,3 \mathrm{a}$ & $13,71 \mathrm{a}$ \\
$500<\mathrm{a}<700$ & $71,8 \mathrm{ab}$ & $59,4 \mathrm{~b}$ & $75,9 \mathrm{~b}$ & $13,6 \mathrm{~b}$ & $13,68 \mathrm{a}$ \\
$\geqslant 700$ & $68,8 \mathrm{~b}$ & $56,0 \mathrm{~b}$ & $73,0 \mathrm{~b}$ & $14,3 \mathrm{~b}$ & $13,59 \mathrm{~b}$ \\
\hline $\mathrm{CV}(\%)$ & 24,8 & 27,1 & 17,2 & 57,3 & 14,2 \\
\hline
\end{tabular}

${ }^{1}$ Médias seguidas pela mesma letra, na coluna, não diferem entre si, pelo teste de Tukey a 5\% de probabilidade.

TABELA 4. Médias das características físicas e fisiológicas de sementes de soja, provenientes de seis regiões produtoras do Brasil, sob o regime de velocidade do cilindro de trilha.

\begin{tabular}{|c|c|c|c|c|c|c|}
\hline $\begin{array}{l}\text { Velocidade do } \\
\text { Cilindro (rpm) }\end{array}$ & $\begin{array}{c}\text { Grau de } \\
\text { Umidade (\%) }\end{array}$ & $\begin{array}{c}\text { Sementes } \\
\text { Quebradas (\%) }\end{array}$ & $\begin{array}{c}\text { Ruptura de } \\
\text { Tegumento }(\%)\end{array}$ & $\begin{array}{c}\text { Dano Mecânico } \\
\text { (TZ 6-8) }\end{array}$ & $\begin{array}{c}\text { Deterioração por } \\
\text { Umidade }(\%)\end{array}$ & $\begin{array}{c}\text { Lesões por } \\
\text { Percevejos }(\%)\end{array}$ \\
\hline$\leqslant 500$ & $13,71 \mathrm{a}$ & $6,7 \mathrm{a}$ & $15,6 \mathrm{a}$ & $8,6 \mathrm{a}$ & $6,0 \mathrm{a}$ & $3,8 \mathrm{a}$ \\
\hline $500<a<700$ & $13,68 \mathrm{a}$ & $9,4 \mathrm{a}$ & $18,9 \mathrm{ab}$ & $10,6 \mathrm{~b}$ & $6,6 \mathrm{a}$ & $4,7 \mathrm{ab}$ \\
\hline$\geqslant 700$ & $13,59 \mathrm{~b}$ & $8,7 \mathrm{~b}$ & $19,9 \mathrm{~b}$ & $14,3 \mathrm{c}$ & $7,8 \mathrm{a}$ & $5,8 \mathrm{~b}$ \\
\hline $\mathrm{CV}(\%)$ & 14,2 & 64 & 40,7 & 57,3 & 13,5 & 23,7 \\
\hline
\end{tabular}

${ }^{1}$ Médias seguidas pela mesma letra, na coluna, não diferem entre si, pelo teste de Tukey a 5\% de probabilidade. 


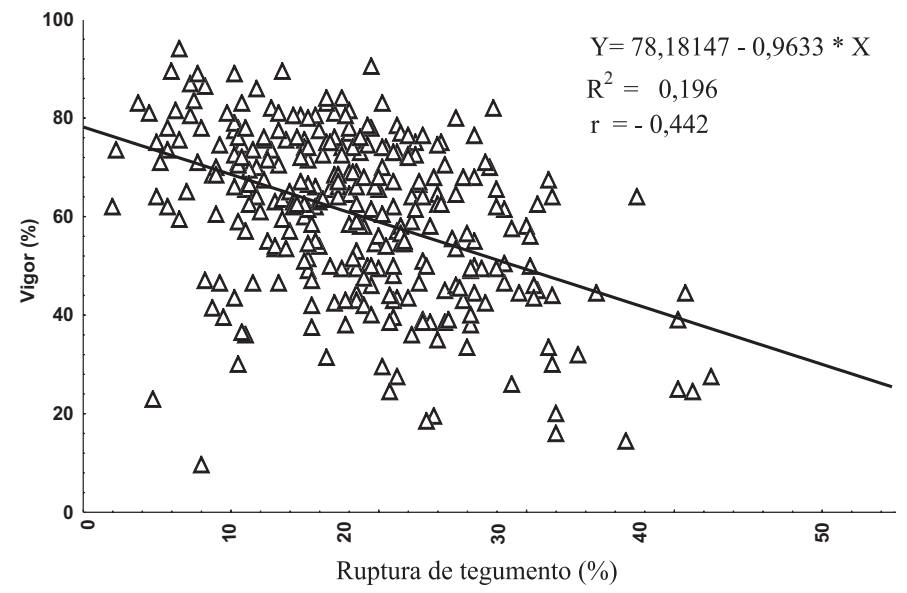

FIGURA3. Análise de correlação e regressão entre vigor (TZ 13) e ruptura de tegumento de sementes de diversas cultivares de soja, produzidas em seis regiões do Brasil.

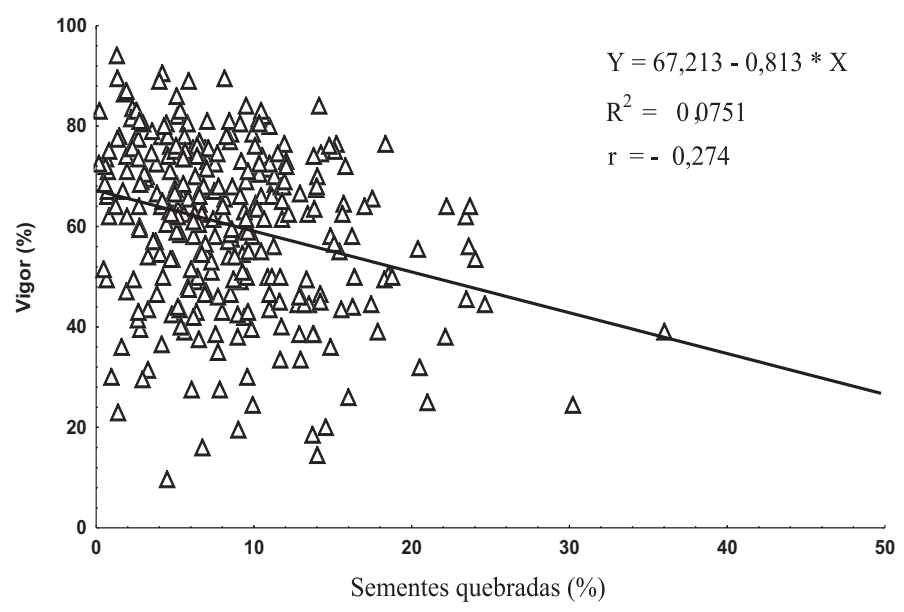

FIGURA4. Análise de correlação e regressão entre vigor (TZ 13) e sementes quebradas (\%) de diversas cultivares de soja, produzidas em seis regiões do Brasil.

no Estado do Mato Grosso (Região Alto Garça), ocorreram reduzidos índices de sementes deterioradas e com lesões de percevejos, obtendo-se assim, padrão razoável de qualidade. Essas regiões são reconhecidas tradicionalmente como produtoras de sementes de alta qualidade, pois estão situadas geograficamente em altitudes superiores a $700 \mathrm{~m}$, com temperatura mais amena no período de maturação da soja, o que favorece a obtenção de sementes com alto potencial fisiológico. Os resultados do estudo mostram ainda, através das análises de correlação e regressão linear (Figuras 7 e 8), que à proporção que aumenta os índices de sementes com sinais de deterioração por umidade (TZ 6-8), verifica-se uma gradual e consistente redução da germinação e do vigor das sementes, ou seja, é uma relação de associação inversamente

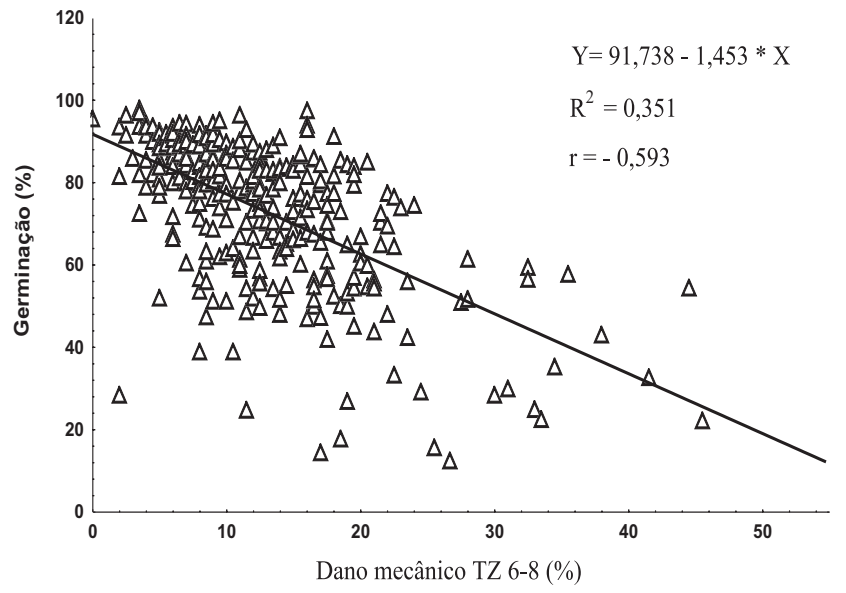

FIGURA5. Análise de correlação e regressão entre germinação (\%) e dano mecânico (TZ 6-8) de sementes de diversas cultivares de soja, produzidas em seis regiões do Brasil.

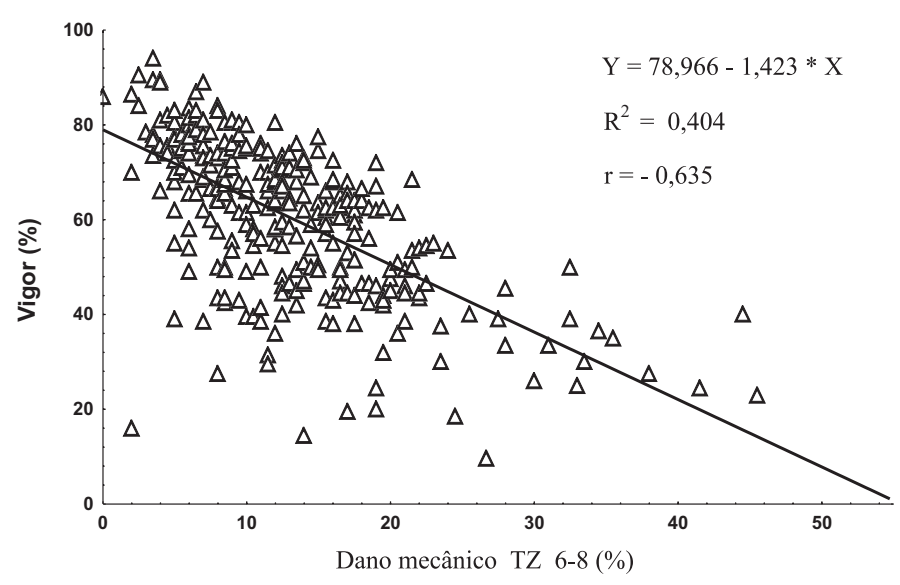

FIGURA 6. Análise de correlação e regressão entre vigor (TZ 1-3) e dano mecânico (TZ 6-8) de sementes de diversas cultivares de soja, produzidas em seis regiões do Brasil.

proporcional.

A deterioração por umidade pode resultar num maior índice de danos mecânicos na colheita, uma vez que sementes deterioradas são extremamente vulneráveis aos impactos mecânicos, mediante observado por França Neto e Henning (1984) e França Neto e Krzyzanowski (2000). Os autores ainda destacam que a deterioração a campo será intensificada pela interação com alguns fungos, como, Phomopsis spp. e Colletotrichum truncatum, que ao infectar as sementes, podem reduzir o vigor e a germinação. Ainda a respeito do assunto, Green et al. (1965), Mondragnon e Potts (1974), Pereira et al. (1979) e Vieira et al. (1982) mostram o efeito marcante da temperatura como parâmetro determinante da baixa qualidade de sementes de soja. Por sua vez, Tekrony et al. (1980) 


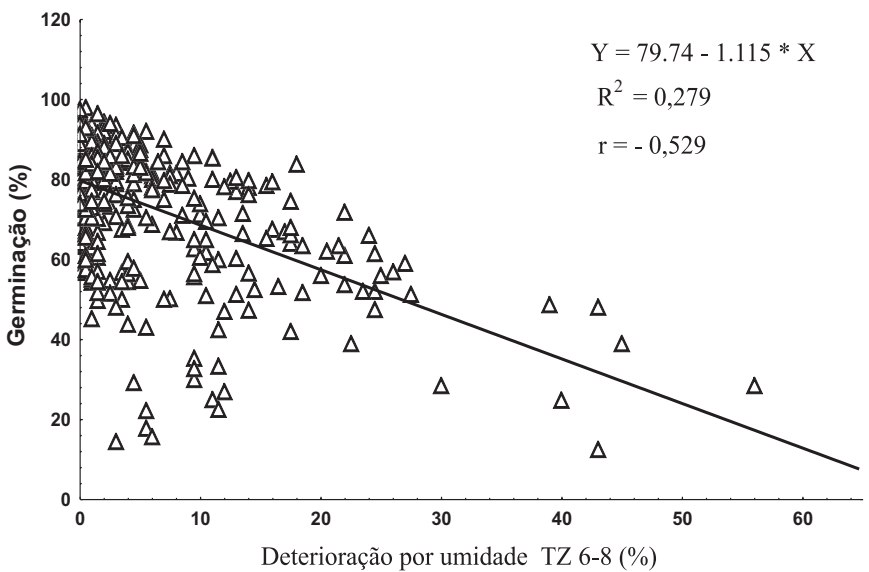

FIGURA 7. Análise de correlação e regressão entre germinação (\%) e deterioração por umidade (TZ 6-8) de sementes de diversas cultivares de soja, produzidas em seis regiões do Brasil.

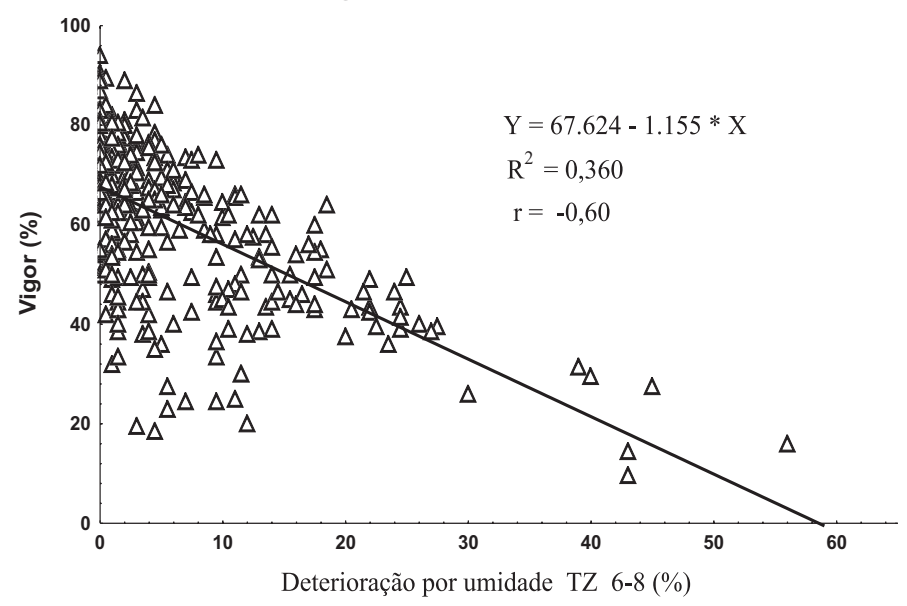

FIGURA 8. Análise de correlação e regressão entre deterioração por umidade (TZ 6-8) e vigor (\%) de sementes de diversas cultivares de soja, produzidas em seis regiões do Brasil.

constatou que à temperatura de $22,2^{\circ} \mathrm{C}$, na ausência total de chuvas, o primeiro declínio no vigor ocorreu após a maturação de campo; já a $12,2^{\circ} \mathrm{C}$ a perda de vigor foi significativa apenas depois de 39 dias. Por outro lado, Dajoz (1981), Costa et al. (1994), França Neto e Krzyzanowski (2000) e Costa et al. (2001) argumentam que, para as condições tropicais brasileiras, onde predominam altas temperaturas e excesso de chuvas no período de maturação da soja, as alternativas mais viáveis para produção de sementes de alta qualidade seriam a escolha de regiões com altitude superior a 700m, onde predomina clima frio e seco no período da maturação a colheita ou o ajustamento na data de semeadura, para ocorrência da maturação em condições ambientais mais favoráveis.

Todavia, deve-se enfatizar que os dados de precipitação pluvial, umidade relativa do ar e de temperatura das regiões estudadas não foram coletadas pela razão do número de locais amostrados e pela amplitude da área abrangida no período de coletas das amostras. Deve-se enfatizar que parte expressiva dessas regiões não dispõe de estações agroclimatológicas que permitissem à obtenção dos dados climáticos comentados.

Quanto aos problemas ocasionados pela incidência de percevejos, os resultados indicaram que a referida praga chegou a atingir níveis críticos, em parte expressiva das amostras de sementes e em determinados locais, conforme ilustrado pelo teste de tetrazólio (Figura 1B). Geralmente sementes com essas características apresentam grande variabilidade de qualidade e com sérios problemas de germinação e vigor.

Historicamente, sabe-se que o dano ocasionado pela picada do inseto, dependendo do local e extensão da área lesionada, como, o eixo-embrionário, torna a semente incapaz de germinar, uma vez que essa região é vital nos processos metabólicos, pois aí, estão inseridas as principais estruturas de crescimento, como, plúmula e sistema radicular que darão origem a futura plântula (França Neto et al., 1998). Observando-se ainda os resultados na Figura 2, vê-se que as regiões norte e oeste do Paraná e os estados de Minas Gerais e Mato Grosso do Sul, manifestaram maiores percentuais de incidência da praga, contribuindo para redução gradual da germinação e do vigor (TZ 1-3). Todavia, a região sul do Paraná e o Estado do Mato Grosso apresentaram menor intensidade de infestação do citado inseto, não chegando a afetar o comportamento fisiológico das sementes (Figura 2).

Por sua vez, os resultados obtidos pelas análises de correlação e regressão linear (Figuras 9 e 10) indicaram que, aparentemente, as sementes de soja lesionadas por percevejos, geralmente apresentam reduções nos potenciais de germinação e vigor (TZ 6-8). A respeito do tema, Panizzi et al. (1979) enfatizam que o período crítico de incidência desse inseto está compreendido entre os estádios de desenvolvimento e de enchimento de vagens. Nessa fase, o controle da praga deve ser realizado quando forem encontrados dois percevejos/metro/ linear, em lavouras comerciais, e um percevejo/metro/linear, em lavouras destinadas a produção de sementes. Os autores citados ainda observaram, nesse estudo, que alta proporção de microrganismos estava associada às sementes danificadas por Piezodorus guildinii, dentre esses, Fusarium sp. que infectou mais de $30 \%$ das sementes lesionadas.

Com relação à qualidade química, os resultados 


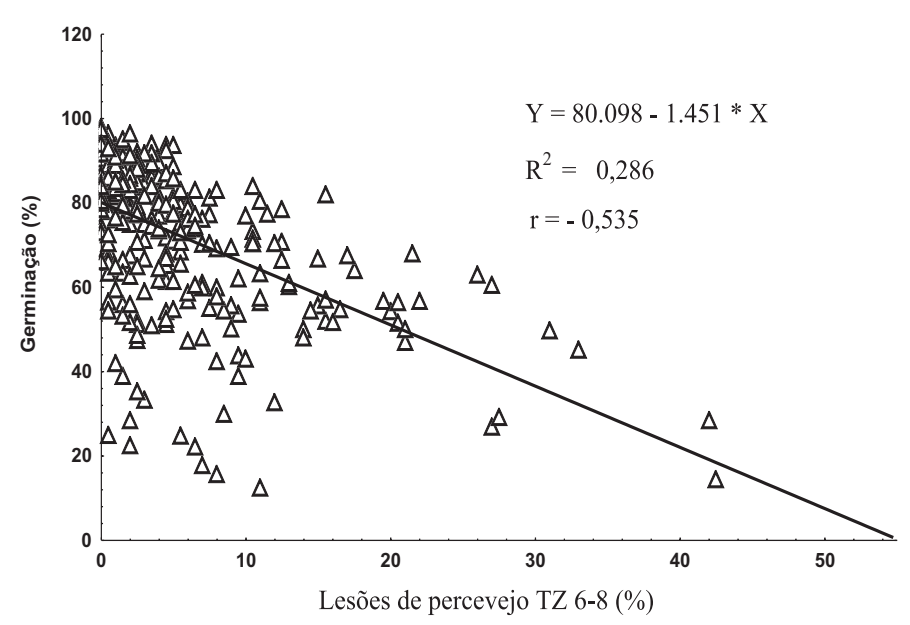

FIGURA9. Análise de correlação e regressão entre germinação (\%) e lesões de percevejos de sementes de diversas cultivares de soja, produzidas em seis regiões do Brasil.

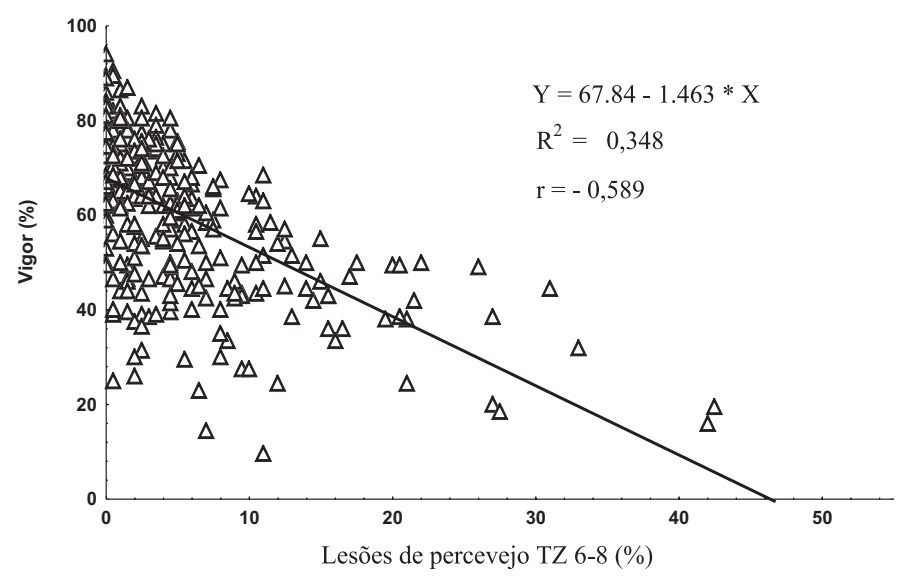

FIGURA 10. Análise de correlação e regressão entre vigor (\%) e lesões de percevejos de sementes de diversas cultivares de soja, produzidas em seis regiões do Brasil. estatísticos indicaram pequenas variações dos níveis de óleo, proteína e respectiva acidez entre as diferentes amostras de sementes e regiões amostradas. Todavia, o teste de Tukey $(\mathrm{P} \leqslant 0,05)$ mostrou que o estado de Minas Gerais apresentou os maiores índices de óleo e proteína, seguido por Mato Grosso do Sul, Mato Grosso e sul do Paraná (Tabela 5). Aparentemente, existem regiões com melhores condições edafoclimáticas para obtenção de maiores percentuais tanto de óleo como de proteína. Detectou-se ainda que o índice de acidez apresentou tendência de elevação em todos os locais analisados. Estes resultados são confirmados por Mandarino et al. (1996) e Costa et al. (2001) que também encontraram variação no conteúdo de óleo e proteína de diferentes genótipos de soja produzidos no Brasil.

De maneira geral, os resultados para as análises de correlação e regressão linear, indicaram que à medida que ocorrem, simultaneamente, acentuados índices de ruptura de tegumento (hipoclorito), de dano mecânico (TZ 6-8), de deterioração por umidade (TZ 6-8), de lesões de percevejos (TZ 6-8) e sementes quebradas, há um gradual e consistente declínio da germinação e do vigor das sementes. Deve-se enfatizar que a maioria das análises de regressão linear apresentou um $\mathrm{R}^{2}$ abaixo do nível esperado, isto pode ser atribuído a outros fatores inerentes as características envolvidas nas análises de qualidade de sementes, o que em alguns casos pode interferir na interpretação dos resultados obtidos. Os resultados para os coeficientes de correlação variaram de $-0,274 \mathrm{a}-0,635$, informando assim, que existe uma relação inversa entre as variáveis respostas pesquisadas (Figuras 3, 4, 5, 6, 7, 8, 9 e 10).

TABELA5. Características químicas de sementes/grãos provenientes da colheita mecânica da soja em seis regiões produtoras do Brasil.

\begin{tabular}{lllllll}
\hline \multicolumn{1}{c}{ Regiões } & Óleo & $(\%)$ & Proteína & $(\%)$ & Acidez do óleo & $(\%)$ \\
\hline Paraná - Sul & $20,0^{1} \mathrm{~cd}$ & $(41)^{2}$ & $38,7 \mathrm{~b}$ & $(41)$ & $1,52 \mathrm{abc}$ & $(38)$ \\
Paraná - Oeste & $21,1 \mathrm{a}$ & $(63)$ & $36,2 \mathrm{~d}$ & $(63)$ & $1,48 \mathrm{abc}$ & $(23)$ \\
Paraná - Norte & $20,6 \mathrm{abc}$ & $(48)$ & $37,2 \mathrm{~cd}$ & $(48)$ & $1,67 \mathrm{a}$ & $(29)$ \\
Minas Gerais & $20,8 \mathrm{ab}$ & $(38)$ & $40,7 \mathrm{a}$ & $(38)$ & $1,56 \mathrm{ab}$ & $(35)$ \\
Mato Grosso do Sul & $19,8 \mathrm{~d}$ & $(39)$ & $38,4 \mathrm{bc}$ & $(39)$ & $1,34 \mathrm{bc}$ & $(40)$ \\
Mato Grosso & $20,2 \mathrm{bcd}$ & $(32)$ & $39,2 \mathrm{~b}$ & $(32)$ & $1,28 \mathrm{c}$ & $(32)$ \\
Média Geral & 20,5 & & 38,1 & & 25,4 & \\
\hline \multicolumn{1}{c}{ CV $(\%)$} & 5,2 & 4,8 & & \\
\hline
\end{tabular}

${ }^{1}$ Médias seguidas pela mesma letra, na coluna, não diferem entre si, pelo teste de Tukey a 5\% de $\quad$ probabilidade.

2 ( ) número de amostras. 


\section{CONCLUSÕES}

Nos Estados do Mato Grosso e região sul do Paraná, existem áreas com potencial climático, para produção de sementes de soja com elevada qualidade fisiológica.

Existem regiões nos Estados de Minas Gerais, Paraná e Mato Grosso que produzem sementes de soja com maiores teores de proteínas e óleo e com acidez relativamente baixa.

\section{REFERÊNCIAS}

ALVAREZ, P.J.C.; KRZYZANOWSKI, F.C.; MANDARINO, J.M.G.; FRANÇA NETO, J.B. Relationship between soybean seed coat lignin content and resistance to mechanical damage. Seed Science and Technology, Zürich, v. 25, n. 2, p. 209-214, 1997.

ANDREWS, C. Mechanical injury on seed. In: SHORT COURSE FOR SEEDSMEN, 1965, Mississippi. Proceedings... Mississippi: Mississippi State University, 1965. p. 25-30.

ATARES, P.A. Novedades en la recoleccin de receales (News on grain harvesting). Maquinas y Tractores, Pamplona, v.1, n. 5, p. 24-35, 1990.

BRASIL. Ministério da Agricultura e da Reforma Agrária. Regras para análise de sementes. Brasília: SNDA/DNDV/CLAV, 1992. 365p.

BUNCH, H.D. Relationships between moisture content of seed and mechanical damage in seed conveying. Seed World, Chicago, v. 86, n. 5, p. 14, 16-17, 1962.

CARBONELL, S.A.M.; KRZYZANOWSKI, F.C.; MESQUITA, C.M. A device to impart impact on soybean seeds for screening genotypes for resistance to mechanical damage. Seed Science and Technology, Zürich, v. 26, n. 1, p. 45-52, 1998.

CARTER, L.J.; HARTWIG, E.E. The management of soybean. Advances in Agronomy, v.14, p.359-419, 1962.

CARVALHO, N.M. Injúria mecânica em sementes: um problema cada vez mais moderno. Seed News, Pelotas, n. 4. p. 34, 2001.

COCHRAN, W.G.; COX, G.M. Experimental designs. 2.ed. New York: 1957.611p.

COSTA, N.P.; MESQUITA, C.M; MAURINA, A.C.C.; FRANÇA NETO, J.B.; KRZYZANOWSKI, F.C; HENNING, A.A. Qualidade fisiológica, física e sanitária de sementes de soja produzidas no Brasil. Revista Brasileira de Sementes, Londrina, v. 25, n.1, p.128132, 2003.

COSTA, N.P.; MESQUITA, C.M.; MAURINA, A.C.; FRANÇA NETO, J.B.; PEREIRA, J.E.; BORDINGNON, J.R.; KRZYZANOWSKI, F.C.; HENNING, A.A. Efeito da colheita mecânica da soja sobre as características físicas, fisiológicas e químicas das sementes produzidas em três estados do Brasil. Revista Brasileira de Sementes, Londrina, v. 23, n. 1, p.140-145, 2001.

COSTA, N.P.; OLIVEIRA, M.C.N.; HENNING, A.A.; KRZYZANOWSKI, F.C.; MESQUITA, C.M.; TAVARES, L.C.V. Efeito da colheita mecânica sobre a qualidade da semente de soja.
Revista Brasileira de Sementes, Brasília, v.18, n. 2, p.232-237, 1996.

COSTA, N.P.; PEREIRA, L.A.G.; FRANÇA NETO, J.B.; HENNING, A.A.; KRZYZANOWSKI, F.C. Zoneamento ecológico do Estado do Paraná para produção de sementes de cultivares precoces de soja. Revista Brasileira de Sementes, Brasília, v.16, n.1, p.12-19, 1994.

DAJOZ, R. Ecologia geral. Petrópolis: Vozes, 1981. 47p.

DELOUCHE, J. Determinants of seed quality. In: SHORT COURSE FOR SEEDMEN, 1967, Mississippi. Proceedings... Mississippi: Seed Technology Laboratory, 1967. v. 14, p. 53-68.

FRANÇA NETO, J.B.; HENNING, A.A. Qualidade fisiológica da semente. Londrina: EMBRAPA-CNPSo, 1984. p. 5-24. (Circular Técnica, 9).

FRANÇA NETO, J.B.; KRZYZANOWSKI, F.C. Produção de sementes de soja: fatores de campo. Seed News, Pelotas, n. 4. p. 20-23, 2000.

FRANÇA NETO, J.B.; KRZYZANOWSKI, F.C.; COSTA, N.P. O teste de tetrazólio em sementes de soja. Londrina: EMBRAPA CNPSo, 1998. 72p. (Documentos, 116).

FREIRE, C.A.L.; CHARNET, E.M.R.; BONVINO, H.; CHARNET, R. Análise de modelos de regressão linear: com aplicações. Campinas: UNICAMP, 1999. 356p. Coleção LivroTexto

GASPARETTO, E.; ZEN, M.; GUADAGNIN, A. Ultra-high speed movie observation of a conventional threshing mechanism (cylinder-concave-rear beater) working on wheat. In: INTERNATIONAL GRAIN AND FORAGE HARVESTING CONFERENCE, 1., 1977, Ames. Proceedings... St. Joseph: ASAE, 1977. p. $104-111$

GREEN, D.E.; CARANAH, L.E.; PINNELL, E.I. Effects on seed moisture content, field weathering, and combine cylinder speed on soybean seed quality. Crop Science, Madison, v. 6, p.7-10, 1965.

MANDARINO, J.M.G.; CARRÃO-PANIZZI, M.C.; ALMEIDA, L.A.; OLIVEIRA, M.C.N. Chemical composition and amino acid profile of high protein Brasilian soybean. In: INTERNATIONAL SOYBEAN PROCESSING AND UTILIZATION CONFERENCE, 2., 1996, Bangkok. Proceedings... Kasetssart: Institute of Food Research and Product Development, 1996. p. 102-108.

MESQUITA, C.M. Mechanics of soybean threshing. 1989. $142 \mathrm{f}$. Dissertation (Doctor of Philosophy)-Interdepartmental Area of Engineering, Agricultural Engineering. University of Nebraska, Lincoln, 1989.

MESQUITA, C.M.; COSTA, N.P.; PEREIRA, J.E.; MAURINA, A.C.; ANDRADE, J.G.M. Colheita mecânica da soja: avaliação das perdas e da qualidade física do grão. Engenharia Agrícola, Jaboticabal, v. 18, n.3, p. 44-53, 1999.

MESQUITA, C.M.; COSTA, N.P.; PORTUGAL. F.A.F. Medidor de sementes quebradas para regulagens das colhedoras. Informativo ABRATES, Londrina, v.9, n.1/2, p.61, 1999.

MONDRAGON, R.L.; POTTS, H.C. Field deterioration of soybean as affected by envionment. Proceedings of the Association Official Seed Analists, v. 64, p. 63-71,1974. 
MOORE, R.P. Effects of mechanical injuries on viability. In: ROBERTS, E.H. (Ed.) Viability of seeds. Syracuse: Syracuse University Press, 1972. p.94-113.

PANIZZI, A.R.; SMITH, J.C.; PEREIRA, L.A.G.; YAMASHITA, J. Efeitos de danos de Piezodorus guildinni (Westwood, 1837) no rendimento e qualidade da soja. In: SEMINÁRIO NACIONAL DE PESQUISA DE SOJA, 1., 1978, Londrina. Anais... Londrina: EMBRAPA CNPSo, 1979. p.59-78.

PEREIRA, L.A.G.; COSTA, N.P.; QUEIROZ, E.F.; NEUMAIER, N.; TORRES, E. Efeito da época de semeadura sobre a qualidade de sementes de soja. Revista Brasileira de Sementes, Brasília, v.1, n.3, p.77-89, 1979.

PREGNOLATTO, W.; PREGNOLATTO, N.P. (Coord.). Normas analíticas do Instituto Adolfo Lutz. 3.ed. São Paulo: Instituto Adolfo Lutz, 1985. v.1, p.25-26,42-45.

SKROMME, L.H. Progress report on twin rotor combine concept of rotary threshing and separation. In: INTERNATIONAL GRAIN AND FORAGE HARVESTING CONFERENCE, 1., 1977, St. Joseph. Mississippi, Proceedings... St. Joseph: ASAE, 1977. p. 188-191.

TEKRONY, D.M.; EGLI, D.B.; PHILLIPS, A.D. Effects of field weathering on the viability and on vigor of soybean seed. Agronomy Journal, Madison, v. 72, n. 5, p.749-753, 1980.

VAUGHAN, C.E. The chlorox test (soybean). Quality assurance technique (Emphasis: Mechanical damage). In: SHORT COURSE FOR SEEDSMEN, 1982. Proccedings... Mississipi: Mississippi State University, 1982. p.117-118.

VIERA, L.R.D.; SEDIYAMA, J.; SILVA, R.E.; SEDIYAMA, C.S.; THIEBAUT, J.T.I.; XIMENES, P. A. Estudo da qualidade fisiológica de semente de soja (Glicine max (L.) Merrill) cultivar UFV-1 em quinze épocas de colheita. In: SEMINÁRIO NACIONAL DE PESQUISA DE SOJA, 2., 1981, Brasília. Anais... Londrina: EMBRAPA/CNPSo, 1982. v. 1, p. 633-644. 